\title{
Functional Capacity and Anemia in the Community Elderly
}

\author{
Barbara Gazolla Macedo, ${ }^{1,2}$, Poliana P. R. Dias², Hanna S. Camara ${ }^{2}$, Carlos Maurício F. Antunes ${ }^{2}$ \\ ${ }^{1}$ Instituto da Previdência dos Sevidores do Estado de Minas Gerais/IPSEMG, Belo Horizonte, Brasil \\ ${ }^{2}$ Instituto de Ensino e Pesquisa da Santa Casa de Belo Horizonte/IEP, Belo Horizonte, Brasil \\ Email: barbragazolla@terra.com.br
}

How to cite this paper: Macedo, B.G., Dias, P.P.R., Camara, H.S. and Antunes, C.M.F. (2017) Functional Capacity and Anemia in the Community Elderly. Advances in Aging Research, 6, 93-100.

https://doi.org/10.4236/aar.2017.66010

Received: September 14, 2014

Accepted: November 1, 2017

Published: November 2, 2017

Copyright $\odot 2017$ by authors and Scientific Research Publishing Inc. This work is licensed under the Creative Commons Attribution International License (CC BY 4.0).

http://creativecommons.org/licenses/by/4.0/

(c) (i) Open Access

\begin{abstract}
Anemia in the elderly population has been associated to clinical manifestations such as functional dependence, low cognitive performance, increased mortality and geriatric syndromes (dementia, delirium, depression and falls). Recent investigations have shown an association between low hemoglobin levels, reduction in muscular strength and physical fitness. The objective of this review was to identify, in the scientific literature, evidence of an association between anemia and functional capacity among older persons. PubMed and Bireme were used as references source. The most relevant evidence pointing towards this association was identified in the epidemiological studies Women's Health and Aging Studies I and II (WHAS I and II). Functional capacity was evaluated by the walking, balance and sitting back and getting out of the chair tests. Elderly women with either 13 or $14 \mathrm{~g} / \mathrm{dl}$ have a better performance compared to women with $12 \mathrm{~g} / \mathrm{dl}$ of hemoglobin, respectively. This study also reported an increase in the mortality risk among women (65 years old and plus) living in community with less than $13.4 \mathrm{~g} / \mathrm{dl}$ of hemoglobin. Participants were followed for 11 years. WHAS I and II investigators suggested a new criterion, already adopted by the World Health Organization (WHO), to define anemia among elderly women. Conclusion: anemia is common among the elderly and may have an involvement in the impairment of their functional capacity. However, in spite of the importance of these findings, it should be emphasized that an etiologic association (anemia as a cause of functional impairment) has yet to be demonstrated.
\end{abstract}

\section{Keywords}

Anemia, Functional Capacity, Fragility, Aging

\section{Introduction}

Anemia is defined by the World Health Organization as hemoglobin levels be- 
low 12.0 and $13.0 \mathrm{~g} / \mathrm{dL}$ for women and men, respectively, although this cut-off point is questioned by several studies [1] [2] [3] [4].

Approximately one third of anemia cases can be associated with nutritional deficiencies (iron, B-12 vitamin and folate), another third with chronic inflammatory and kidney diseases and the last third does not show association to specific etiologies [2] [3] [4].

Anemia is a common health problem among older adults, particularly in persons aged 65 and over and its etiology is multifactorial. It is estimated that $10 \%$ of the elderly in the community has anemia, as well as more than $50 \%$ of those institutionalized. Anemia prevalence increases with age, it is higher than $20 \%$ for those aged 85 [2]-[8]. A systematic review on anemia prevalence in the elderly has shown a percentage of $15 \%$ and $14 \%$ for men and women, respectively [5]. Men tend to develop anemia later in life when compared to women. Anemia is 3-fold more common in blacks than whites and latinos [8]. In Brazil there are few studies about the prevalence of anemia in the elderly. One particular study from Camaragibe, in Pernambuco State, with 284 participants from the Family Health Program found an anemia prevalence of $11 \%$ while the SABE study, conducted in São Paulo City, found an anemia prevalence of $7.7 \%$, mainly among the eldest elderly [9] [10].

Several studies have proved anemia to be an independent risk factor for increased morbidity and mortality and for a decreased quality of life amongst the elderly in the community. This low concentration of hemoglobin levels is also associated to a higher risk of hospitalization, delirium, depression, falls, functional and cognitive decline [5] [11] [12] [13] [14].

Some epidemiological studies amongst the elderly in the community have associated anemia to a reduction of the functional capacity, which also increases the risk of falling. This increased risk of falling happens mainly due to a physical impairment in the performance daily living activities, causing a reduction in muscle force production, balance, gait speed and mobility in general [15]-[23].

Even though not being considered as a consequence of the aging process, anemia is commonly reported among the elderly population and its treatment, frequently, it is overlooked.

This study aims at reviewing and evaluating epidemiological studies about the impact of anemia in the functional capacity of the elderly in the community.

\section{Methodology}

This study has reviewed the biomedical literature over the last 15 years, from PubMed and Lilacs databases. The terms used in the revision were anemia, functional capacity, frailty, and aging. Inclusion criteria were articles published in English, Spanish or Portuguese on people aged 65 and over. The selected articles were mainly epidemiological studies or population-based studies on unexplained anemia. The excluded articles associated anemia to loss of functional capacity in hospitalized or institutionalized elderly, as well as anemia related to other diseases, such as cancer, cardiac and renal insufficiency among others. 


\section{Results and Discussion}

Some longitudinal epidemiological studies have tried to establish a relationship between anemia, functional capacity, mortality and quality of life amongst the elderly in the community [15]-[34] (See Chart 1); however, clinical intervention studies comparing the functional capacity before and after the treatment of anemia were not well elucidated.

The metric parameters used in those papers were gait speed, muscle strength, balance, mobility and cognition. Anemic elderly adults have a reduced gait speed, muscle force, balance and daily life activities performance.

One of the most impactful epidemiological studies in this field is Women's Health Aging Study (WHAS I and II). WHAS assessed the functional capacity of women ages 65 and over using the walking speed test, sitting and getting up from the chair test and balance tests. The women who had hemoglobin levels between 13.0 and $14.0 \mathrm{~g} / \mathrm{dL}$ had better functional test results than the women who had hemoglobin levels of $12.0 \mathrm{~g} / \mathrm{dL}$. The study also reported an increase of mortality risk for the women who had hemoglobin levels inferior to $13.4 \mathrm{~g} / \mathrm{dL}$; they lived in their own houses and were monitored for an average of 11 years. The conclusions of this study suggest a review in the cut-off point for the definition of anemia by the World Health Organization [24].

A study, based on the WHAS, assessed the quality of life and the functional capacity of 328 senior people in the community. The presence of anemia was associated to a reduction in muscle strength, an increased number of disabilities, fatigue, and depressive symptoms. A low concentration of hemoglobin levels was associated to a worse quality of life even amongst the elderly who had mild anemia (hemoglobin levels between 10.0 to $12.0 \mathrm{~g} / \mathrm{dL}$ ). The results were the same after controlling, in regression analysis, socio-demographic variables and the presence of chronic diseases [16].

Chart 1. Epidemiological study: anemia and functional capacity.

\begin{tabular}{cccc}
\hline Study & Local & Participants & Age \\
\hline $\begin{array}{c}\text { Cardiovascular Health Study (CHS) } \\
\text { Chicago Health Aging Protect (CHAP) }\end{array}$ & USA & 5888 & 65 and + \\
$\begin{array}{c}\text { Established Population for } \\
\text { Epidemiologic Studies (EPESE) }\end{array}$ & USA & 1806 & 65 and + \\
$\begin{array}{c}\text { Invecchire in Chianti (In Chianti) } \\
\text { Leiden 85-plus Study (Leiden) }\end{array}$ & Chianti-Itália & 1156 & 71 and + \\
Milman Study & Leiden-Holanda & 1258 & 85 and + \\
$\begin{array}{c}\text { Third National Health and Nutrition } \\
\text { Examination Survey (NHANES III) }\end{array}$ & Alemanha & 359 & 807 and + \\
Women's Health and Aging Studies \\
(WHAS I e II)
\end{tabular}


Another study, assessed the functional capacity of 1156 senior people participating in the InChianti, a representative population-based epidemiological study of the elderly. Inferior limb muscle strength and hand palm pressing strength were measured by the researchers, as well as daily life activities and physical performance. The tests used were the four-meter walking, sitting and getting up from the chair and balance. Anemic elderly adults had a reduced performance in all the tests, even after control of gender, age and comorbidity variables were applied [17].

An epidemiological prospective study with 562 people belonging to the Leiden 85-plus Study. The study followed the participants (ages 85 and over) for 5 years, assessing their functional capacity in daily life activities, cognitive function and depressive symptoms. It was possible to relate anemia in very old people to an increased risk of death, regardless of comorbidity presence. However, the association between anemia and functional decline seemed to be mainly due to the presence of co-morbidities [19].

The association between anemia and cognitive impairment has been described in the biomedical literature. A longitudinal study with 1435 senior people in the community, ages 75 - 95, found an independent association between anemia and an increased risk of new dementia diagnostics. The presence of anemia was also associated to cognitive deficits connected primarily to executive functions. Executive functions include abilities such as planning, solving problems, organizing and directing the body to carry out daily activities. Deficits in executive functions also occur in old people that do not have dementia; they may precede deficits in other domains of cognitive function and represent a risk factor for the decline of daily activities. An investigation assessed the association between mild anemia and executive functions in 364 active women, age 70 - 80, in the community. The results were four times worse compared to the results of women without anemia, after adjusting the other variables. Data from a prospective population project called Epidemiological Studies of the Elderly (EPESE) with 1744 senior people in the community also showed an association between anemia and decline of cognitive function [24] [25] [26].

An increase in the concentration of inflammatory cytokines, associated to an increase of erythropoietin was followed by a reduction in the response of erythropoietin to anemia [27]. Similar findings were reported in the Baltimore Longitudinal Study of Aging [28]. Those studies suggest a double response of erythropoietin to inflammatory cytokines: an increased initial production of erythropoietin when there is a normal level of hemoglobin followed by a reduction in the response of erythropoietin to a fall in the level of hemoglobin. This relative erythropoietin deficiency, similar to the relative insulin deficiency in Diabetes type 2 , is amplified by a bigger resistance to erythropoietin by its ancestors. Erythropoietin is also mediated by Interleukin 6 (IL-6), an interleukin that acts as both a pro-inflammatory cytokine and an anti-inflammatory myokine, and by the increased plasma levels of hepcidin, which impairs the mobilization of iron from its deposits. In previous studies, it was shown that increased plasma 
levels of inflammatory cytokines, especially IL-6, was associated to an increase in mortality rates, functional dependency and a great number of geriatric syndromes, including dementia and osteoporosis [5] [24] [27] [28].

Even though anemia is not a natural consequence of the aging process it is often found in the elderly and it has been held responsible for many symptoms that contribute negatively to the health of this age group. Hence, studies on anemia in the elderly have significantly grown in the last few years [29] [29] [31]. There are at least seven studies demonstrating that anemia is an independent risk factor for mortality in the elderly [28]-[31] [35] [36] [37].

Studies conducted on the elderly population associate anemia to several symptoms such as: loss of muscle strength, weakness, fatigue, increased risk of falls, decline of cognitive function and depression [28]-[31] [35] [38] [39]. In cases of chronic anemia, the spontaneous complaints from the elderly are less exuberant than the ones from youngsters; without noticing, the elderly practically stop their physical activity.

In the WHAS, EPESE and In Chianti studies the levels of hemoglobin in people over 65 is inversely proportional to increased limitations of daily life activities and mobility issues, especially bellow $13.0 \mathrm{~g} / \mathrm{dL}$. These discoveries suggest that even a mild anemia may cause serious consequences for the functional independence of the elderly [17] [25] [35] [40].

There is an important association between anemia and frailty reported in the literature [27] [28]. Hematopoiesis is regulated by the interleukins. In some older persons, the secretion and the response to erythropoietin may be damaged, due to an increased plasma concentration of IL- 6 and other inflammatory cytokines. Markers of chronic inflammation are probably involved in both phenomena (anemia and frailty), even if there isn't any inflammatory disease involved. The occurrence of those markers seems to be triggered by an age associated malfunction of certain pro-inflammatory cytokines, including IL-6. The IL-6 causes anemia and frailty from a clinical point of view [5] [13] [27] [28].

\section{Final Considerations}

Anemia is commonly reported in the elderly and frequently overlooked. It may be associated to complications as the decline of functional capacity. Anemia is often not diagnosed in the elderly and they simply do not get adequate treatment.

The hypothesis of anemia being both a cause and consequence of aging cannot be discarded. More investigations are needed to evaluate the impact of anemia and its treatment in functional impairment. Large cohort studies, using more specific hemoglobin level definition and functional capacity evaluation, should be conducted. An adequate treatment for anemia may break this vicious cycle and postpone the complications of aging.

\section{Acknowledgements}

The authors acknowledge the support of Fundação de Amparo à Pesquisa doEs- 
tado de Minas Gerais (FAPEMIG) and Conselho Nacional de Desenvolvmento Cientifico e Tecnologico (CNPq), Brazil.

\section{References}

[1] World Health Organization (1968) Nutritional Anaemias. Report of a WHO Scientific Group (Technical Report Series No. 405). The Organization, Geneva.

[2] Bianchi, E. (2014) Anemia in the Elderly Population. Journal of Hematology \& Oncology, 3, 95-106. https://doi.org/10.14740/jh182w

[3] Ania, B.J., Suman, V.J., Fairbanks, V.F., Rademacher, D.M. and Melton, L.J. (1997) Incidence of Anemia in Older People: An Epidemiologic Study in a Well Defined Population. Journal of the American Geriatrics Society, 45, 825-831. https://doi.org/10.1111/j.1532-5415.1997.tb01509.x

[4] Gaskell, H., Derry, S., Moore, R.A. and McQuay, H.J. (2008) Prevalence of Anaemia in Older Persons: Systematic Review. BMC Geriatrics, 8, 1.

http://www.biomedcentral.com/1471-2318/8/1 https://doi.org/10.1186/1471-2318-8-1

[5] Begh, C., Wilson, A. and Ershler, W.B. (2004) Prevalence and Outcomes of Anemia in Geriatrics: A Systematic Review of the Literature. The American Journal of Medicine, 116, 3S-10S. https://doi.org/10.1016/j.amjmed.2003.12.009

[6] Röhrig, G. (2016) Anemia in the Frail, Elderly Patient. Clinical Interventions in Aging, 11, 319-326. https://doi.org/10.2147/CIA.S90727

[7] Contreras, M., Formiga, F., Ferrer, A., Chivite, D., Padrós, G. and Montero, A. (2015) Grupo Octabaix. Profile and Prognosis of Patients over 85 Years Old with Anemia Living in the Community. Octabaix Study. Revista Española de Geriatría y Gerontología, 50, 211-215. https://doi.org/10.1016/j.regg.2014.11.004

[8] Barbosa, D.L., Arruda, I.K.G. and Diniz, A.S. (2006) Prevalêcia e caracterização da anemia em idosos do Programa de Saúde da Familia [Prevalence and Characteristics of Anemia in an Elderly Population Attending a Health Family Program]. Revista Brasileira de Hematologia e Hemoterapia, 28, 288-292. https://doi.org/10.1590/S1516-84842006000400014

[9] Corona, L.P., et al. (2014) Anemia and Associated Factors in Older Adults. Saúde Pública, 48, 723-731. https://doi.org/10.1590/S0034-8910.2014048005039

[10] Bosco, R.M., et al. (2013) Anemia e capacidade funcional em idosos brasileiros hospitalizados [Anemia and Functional Capacity in Elderly Brazilian Hospitalized Patients]. Cadernos de Saúde Pública, 29, 1322-1332. https://doi.org/10.1590/S0102-311X2013000700007

[11] Thaler-Kall, K., et al. (2014) Association between Anemia and Falls in Community Dwelling Older People. BMC Geriatrics, 14, 29.

https://doi.org/10.1186/1471-2318-14-29

[12] Lipschitz, D. (2003) Medical and Functional Consequences of Anemia in the Elderly. Journal of the American Geriatrics Society, 51, S10-S13. https://doi.org/10.1046/j.1532-5415.51.3s.6.x

[13] Goodnough, L.T. and Schrier, S.L. (2014) Evaluation and Management of Anemia in the Elderly. American Journal of Hematology, 89, 88-96. https://doi.org/10.1002/ajh.23598

[14] Bose, S.K., Andrews, J. and Roberts, P.D. (1970) Haematological Problems in a Geriatric Unit with Special Reference to Anaemia. Clinical Gerontologist (Base), 12, 339-346. https://doi.org/10.1159/000245299 
[15] Cesari, M., Penninx, B.W., Lauretani, F., Russo, C.R., Carter, C. and Baudinelli, S. (2004) Hemoglobin Levels and Skeletal Muscle: Results from the in CHIANTI Study. The Journals of Gerontology. Series A, Biological Sciences and Medical Sciences, 59A, 249-254. https://doi.org/10.1093/gerona/59.3.M249

[16] Thein, M. (2009) Diminished Quality of Life and Physical Function in Community-Dwelling Elderly with Anemia. Medicine (Baltimore), 88, 107-114.

[17] Penninx, B.W., Pahor, M., Cesari, M. and Corsi, A.M. (2004) Anemia Is Associated with Disability and Decreased Physical Performance and Muscle Strength in the Elderly. Journal of the American Geriatrics Society, 52, 719-724. https://doi.org/10.1111/j.1532-5415.2004.52208.x

[18] Penninx, B.W., Pahor, M., Woodman, R.C. and Guralnik, J.M. (2006) Anemia in Old Age Is Associated with Increased Mortality and Hospitalization. The Journals of Gerontology: Series A, Biological Sciences and Medical Sciences, 61, 474-479. https://doi.org/10.1093/gerona/61.5.474

[19] Den Elzen, W.P.J., Willems, J.M., Westendorp, R.G.J., Craen, A.J.M., Assendelft, W.J.J. and Gussekloo, J. (2009) Effect of Anemia and Comorbidity on Functional Status and Mortality in Old Age: Results from the Leiden 85-Plus Study. CMAJ, 181, 151-157. https://doi.org/10.1503/cmaj.090040

[20] Denny, S.D., Kuchibhatla, M.N. and Cohen, H.J. (2006) Impact of Anemia on Mortality, Cognition, and Function in Community-Dwelling Elderly. American Journal of Medicine, 119, 327-334.

[21] Röhrig, G., et al. (2016) Association between Hematologic Parameters and Functional Impairment among Geriatric Inpatients: Data of a Prospective Cross-Sectional Multicenter Study. Maturitas, 90, 37-41.

[22] Gómez, R.S., Remacha, S.A.F. and Muñoz Gómez, M. (2017) Anaemia in the Elderly. Clinical Medicine.

[23] Le, C.H. (2016) The Prevalence of Anemia and Moderate-Severe Anemia in the US Population (NHANES 2003-2012). PLoS ONE, 11, e0166635.

[24] Chaves, P.H., Ashar, B., Guralnik, J.M. and Friedl, L.P. (2002) Looking at the Relationship between Hemoglobin Concentration and Prevalent Mobility Difficulty in Older Women. Should the Criteria Currently Used to Define Anemia in Older People Be Reevaluated? Journal of the American Geriatrics Society, 50, 1257-1264. https://doi.org/10.1046/j.1532-5415.2002.50313.x

[25] Chaves, P.H.M., Carlson, M.C., Ferrucci, L., Guralnik, J.M., Semba, R. and Fried, L.P. (2006) Association between Mild Anemia and Executive Function Impairment in Community Dwelling Older Women: The Women's Health and Aging Study II. Journal of the American Geriatrics Society, 54, 1429-1435. https://doi.org/10.1111/j.1532-5415.2006.00863.x

[26] Lucca, U., Tettamanti, M., Mosconi, P., Apolone, G., Gandini, F., Nobili, A., Tallone, M.V., Detoma, P., et al. (2008) Association of Mild Anemia with Cognitive, Functional, Mood and Quality of Life Outcomes in the Elderly: The "Health and Anemia" Study. PLoS ONE, 3, e1920. https://doi.org/10.1371/journal.pone.0001920

[27] Ferrucci, L., et al. (2005) Proinflammatory State and Circulating Erythropoietin in Persons with and without Anemia. American Journal of Medicine, 118, 1288.

[28] Ershler, W.B., Artz, A.S. and Kandahari, M.M. (2001) Recombinant Erythropoietin Treatment of Anemia in Older Adults. Journal of the American Geriatrics Society, 49, 1396-1397. https://doi.org/10.1046/j.1532-5415.2001.49275.x

[29] Ng, T.P., Niti, M., Chiam, P.C. and Kua, E.H. (2006) Prevalence and Correlates of 
Functional Disability in Multiethnic Elderly Singaporeans. Journal of the American Geriatrics Society, 54, 21-29. https://doi.org/10.1111/j.1532-5415.2005.00533.x

[30] Gill, T.M., Allore, H.G., Hardy, S.E. and Guo, Z.G. (2006) The Dynamic Nature of Mobility in Older Persons. Journal of the American Geriatrics Society, 54, 248-254. https://doi.org/10.1111/j.1532-5415.2005.00586.x

[31] Leveille, S.G., Penninx, B.W., Melzer, D., Izmirlian, G. and Guralnik, J.M. (2000) Sex Differences in the Prevalence of Mobility Disability in Old Age: The Dynamics of Incidence, Recovery, and Mortality. Journal of Gerontology Series B: Psychological Sciences and Social Sciences, 55B, S41-S50.

[32] Milman, N., Pedersen, A.N., Ovesen, L. and Schroll, M. (2008) Hemoglobin Concentrations in 358 Apparently Healthy 80-Year-Old Danish Men and Women: Should the Reference Interval Be Adjusted for Age? Aging Clinical and Experimental Research, 20, 8-14. https://doi.org/10.1007/BF03324741

[33] Zakai, N.A., et al. (2013) Hemoglobin Decline, Function, and Mortality in the Elderly: The Cardiovascular Health Study. American Journal of Hematology, 88, 5-9. https://doi.org/10.1002/ajh.23336

[34] Dong, X., et al. (2008) A Population-Based Study of Hemoglobin, Race, and Mortality in Elderly Persons. Journal of Gerontology, 63A, 873-878.

https://doi.org/10.1093/gerona/63.8.873

[35] Inzitari, M., Di Carlo, A., Marzia, B., Pracucci, G., Maggi, S., Gandolfo, C., et al. (2006) Risk and Predictors of Motor-Performance Decline in a Normally Functioning Population-Based Sample of Elderly Subjects: The Italian Longitudinal Study on Aging. Journal of the American Geriatrics Society, 54, 318-324. https://doi.org/10.1111/j.1532-5415.2005.00584.x

[36] Yamada, M., Wong, F.L. and Suzuki, G. (2003) RERF's (Radiation Effects Research Foundation) Adult Health Study. Longitudinal Trends of Hemoglobin Levels in a Japanese Population. European Journal of Haematology, 70, 129-135. https://doi.org/10.1034/j.1600-0609.2003.00031.x

[37] Hebert, R., Brayne, C. and Spiegelhalter, D. (1999) Factors Associated with Functional Decline and Improvement in a Very Elderly Community-Dwelling Population. American Journal of Epidemiology, 150, 501-510. https://doi.org/10.1093/oxfordjournals.aje.a010039

[38] Macedo, B.G., Dias, P.P.R., Camara, H.S. and Antunes, C.M.F. (2017) Anemia in the Elderly: Neuropsychiatric Repercussions. Advances in Aging Research, 6, 11-16. https://doi.org/10.4236/aar.2017.61002

[39] Atti, A.R., Palmer, K., Volpato, S., Zuliani, G., Winblad, D. and Fratiglioni, L. (2006) Anemia Increases the Risk of Dementia in Cognitively Intact Elderly. Neurobiology of Aging, 27, 278-284.

[40] Semba, R.D., et al. (2007) Types of Anemia and Mortality among Older Disabled Women Living in the Community: The Women's Health and Aging Study I. Aging Clinical and Experimental Research, 19, 259-264.

https://doi.org/10.1007/BF03324699 